Article

\title{
Determination of the Total Polyphenols Content and Antioxidant Activity of Echinacea Purpurea Extracts Using Newly Manufactured Glassy Carbon Electrodes Modified with Carbon Nanotubes
}

\author{
Florin Banica ${ }^{1}$, Simona Bungau $\left.{ }^{1, *} \mathbb{(}\right)$, Delia Mirela Tit ${ }^{1}\left(\mathbb{D}\right.$, Tapan Behl ${ }^{2, *}$, Pavel Otrisal ${ }^{3}(\mathbb{D}$, \\ Aurelia Cristina Nechifor ${ }^{4}$, Daniela Gitea ${ }^{1}$, Flavia-Maria Pavel ${ }^{5}$ and Sebastian Nemeth ${ }^{1}$ \\ 1 Department of Pharmacy, Faculty of Medicine and Pharmacy, University of Oradea, 29 N. Jiga St., \\ 410028 Oradea, Romania; florinbanica1@gmail.com (F.B.); mirela_tit@yahoo.com (D.M.T.); \\ gitea_daniela@yahoo.co.uk (D.G.); sebinemeth@yahoo.com (S.N.) \\ 2 Chitkara College of Pharmacy, Chitkara University, Punjab 140401, India \\ 3 Faculty of the Physical Culture, Palacký University Olomouc, 77111 Olomouc, Czech Republic; \\ pavel.otrisal@upol.cz \\ 4 Department of Analytical Chemistry, Faculty of Applied Chemistry and Materials Science University \\ Politehnica of Bucharest,1-7 Polizu St., 011061 Bucharest, Romania; aureliacristinanechifor@gmail.com \\ 5 Department of Preclinical Disciplines, Faculty of Medicine and Pharmacy, University of Oradea, \\ 410073 Oradea, Romania; flavia.bontze@gmail.com \\ * Correspondence: sbungau@uoradea.ro (S.B.); tapanbehl31@gmail.com (T.B.); \\ Tel.: +40-726-776588 (S.B.); +91-852517931 (T.B.)
}

Received: 17 June 2020; Accepted: 8 July 2020; Published: 13 July 2020

\begin{abstract}
A sensitive electrochemical method was used for the determination of the total phenolic content and antioxidant activity of Echinacea purpurea extracts. In this study, 3 glassy carbon electrodes (GCE) were used: one unmodified and the other two newly manufactured glassy carbon electrodes modified with carbon nanotubes (CNTs) and chitosan (CS) in different concentrations, having the following composition: $1 \mathrm{mg} / \mathrm{mL} \mathrm{CNTs/CS} \mathrm{5 \% /GCE} \mathrm{and} 20 \mathrm{mg} / \mathrm{mL} \mathrm{CNTs/CS} \mathrm{0.5 \% /GCE.}$ The determinations were performed on 3 different pharmaceutical forms (capsules, tablets and tincture), which contain E. pururea extract from the root or aerial part of the plant. Standard chicoric and caftaric polyphenolic acids, as well as food supplements extracts, were characterized using voltammetry, in a Britton-Robinson (B-R) electrolyte buffer. The modified $1 \mathrm{mg} / \mathrm{mL}$ CNTs/CS 5\%/GCE electrode has superior properties compared to the other two (the unmodified and $20 \mathrm{mg} / \mathrm{mL} \mathrm{CNTs} / \mathrm{CS}$ 0.5\%/GCE-modified) electrodes used in the study. Echinacea tincture had the highest antioxidant capacity and the biggest total amount of polyphenols (28.72 mg/equivalent of $500 \mathrm{mg}$ powder). Echinacea capsules had the lowest antioxidant capacity, but also the lowest total amount of polyphenols (19.50 mg/500 mg powder); similarly, tablets had approximately the same values of polyphenols content (19.80 mg/500 mg powder), and also antioxidant capacity. The total polyphenol content was consistent with the one indicated by the manufacturers. Pulse-differential cyclic voltammetry represents a rapid, simple and sensitive technique to establish the entire polyphenolic amount and the antioxidant activity of the E. purpurea extracts.
\end{abstract}

Keywords: polyphenols; antioxidant activity; Echinacea purpurea extracts; glassy carbon electrode (GCE); carbon nanotubes (CNTs) 


\section{Introduction}

Echinacea purpurea (L.) Moench, which is included in the Asteraceae (Compositae) family, is acknowledged to be one of the most significant medicinal plants worldwide. The extracts obtained from different parts of Echinacea purpurea were traditionally used in North America as remedies for wounds and different types of infections, and came to be extremely well-known herbal remedies [1]. Dietary supplements and extracts of this plant present antiviral, antibacterial, antifungal and antioxidant action, different parts of many plants being used from antiquity [2] to treat viral and inflammatory illnesses [1,3]. Many studies have revealed that Echinacea extracts promote the secretion of cytokines like interleukins (Il-1, Il-6, Il-8, Il-12), tumour necrosis factor alfa (TNF- $\alpha$ ) and nitric oxide (NO), and an increased activation of macrophages [4-6]. The most significant potential active substances found in E. purpurea are represented by polyphenols-derivatives of caffeic acid, as follows: chicoric acid, chlorogenic acid, caftaric acid, echinacoside and cynarin [7,8].

All species of Echinacea that were studied presented radical scavenging action, the most efficient being E. purpurea [8]. The principal component of Echinacea root-chicoric acid (Figure 1A)is considered a significant antioxidant in the plant, being a suitable marker for the quality of products containing this plant, due to its powerful immunostimulatory, antioxidant and antiviral characteristics and due to its degradation susceptibility $[9,10]$. Another important phenolic component in E. purpurea is caftaric acid (Figure 1B), which inhibits the oxidation of low-density lipoprotein (LDL) cholesterol isolated from human plasma and removes 2,2-diphenyl-1-picrylhydrazyl (DPPH) free radicals in a cell-free assay [11].<smiles>O=C(/C=C/c1ccc(O)c(O)c1)OC(C(=O)O)C(OC(=O)/C=C/c1ccc(O)c(O)c1)C(=O)O</smiles>

A<smiles>O=C(/C=C/c1ccc(O)c(O)c1)O[C@H](C(=O)O)[C@H](O)C(=O)O</smiles>

B

Figure 1. Structural formula: (A) Chicoric acid, (B) Caftaric acid.

Various researchers have focused on studying the antioxidant activity and polyphenolic composition of Echinacea extracts using different methods, such as High-Performance Liquid Chromatography (HPLC) and Ultra-High Performance Liquid Chromatography (UPLC) techniques [12-14], colorimetric methods-chemical 2,2-diphenyl-1-picrylhydrazyl (DPPH) and 2,2'-Azino-bis(3-ethyl-benzothiazoline6-sulfonic acid) (ABTS) - radical scavenging techniques $[3,8,10]$. In general, chemical methods need various preparation stages and extended duration to finish the measurement. Nevertheless, prolonged steps and complexness in some of the methods above makes them inappropriate for precise determination. Therefore, rapid and simple techniques have become a significant requirement. Lately, it has been noted that electrochemical methods may be established to determine the polyphenolic composition [15-18]. Electrochemical methods that are used for the determination are simple and sensitive. Furthermore, voltammetric methods show very good functioning in terms of enhanced sensitivity, reduced overpotential and decreased detection limit $[19,20]$. Square Wave Voltammetry was used to determination of the antioxidant activity in Echinacea purpurea roots [21].

At present, carbon nanotubes (CNTs) are extensively used as modifiers due to their physicochemical attributes, distinctive structure and compatibility with biological molecules. CNTs are considered an essential category of nanomaterials. Because of their specific properties-mechanical, chemical and electrical - they have been seen as analytical tools, being considered as rolled up graphite sheets connected by Van der Waal's bonds [22]. The reactivity of graphene sheet as compared to the nanotubes' chemical reactivity improved as a direct outcome of the CNT surface curvature [23]. 
Recent studies showed that transforming electrodes by adding carbon CNTs makes the electrochemical processes that involve biomolecules easier and enhances the measured signal. The development of electrochemical sensors has attracted considerable attention as a low-cost method for the sensitive detection of a variety of pharmaceutical analytes. Since the discovery of CNTs in 1991 [24], research on them has grown rapidly. In recent years, CNTs have also been used as electrode-modified materials because they offer unique advantages, including enhanced electronic properties, a large edge plane/basal plane ratio, and electron transfer reactions [25]. Thus, CNTs-based sensors generally have higher sensitivities in a low concentration or in the complex matrix, lower limits of detection and faster electron transfer kinetics than traditional carbon electrodes.

Many factors need to be investigated in order to create an optimal CNTs-based sensor. Electrode performance can be influenced by the pretreatment of the nanotube, CNTs surface modification, the method of electrode attachment and the addition of electron mediators. With the further development of CNTs and nanotechnology, studies on preparation, properties and application of CNTs-based modified electrodes have still been a hot topic attracting lots of researchers around the world. This research focused on the application of CNTs-modified electrodes in different pharmaceutical analytes, which mainly includes the electrochemical studies on weak basic/acidic pharmaceuticals and other related small biological molecules. The physical and catalytic properties make CNTs ideal for use in sensors with extremely varied applications [26]. Most notably, CNTs display high electrical conductivity, chemical stability and mechanical strength [27]. A disadvantage of using CNTs can be considered the low wettability of their surface, which induces a weak surface bond [28]. This involves improving the mechanical properties of CNTs with chitosan (CS), a natural polysaccharide used in pharmaceutical [29] and medical applications [30,31], having the role of fixing CNTs to the glassy carbon electrode (GCE) surface and to functionalize the CNTs in order to increase their electroactive surface.

The aim of this study was to determine the total polyphenolic content and, secondary, the antioxidant capacity of commercial food supplements containing extracts of Echinacea purpurea, through differential pulse voltammetry, using both an unmodified glassy carbon electrode (GCE) and two modified with CNTs. The novelty of the paper consists precisely in the use of these glassy carbon electrodes modified with CNTs, newly manufactured by the authors, which, after being characterized by cyclic voltammetry, were observed to generate oxidation/reduction peaks, higher than other types of electrodes. The method of analysis with the modified electrode is original due to the fact that, to our knowledge, no voltammetric dosing of polyphenols has been performed using electrodes modified with CNTs and CS.

\section{Materials and Methods}

\subsection{Reagents}

In this research, standard chicoric and caftaric polyphenolic acids, as well as food supplement extracts, were characterized using voltammetry, in a Britton-Robinson (B-R) electrolyte buffer. The characteristics of the standard substances and reagents that were used are described in Table 1. Double-distilled water was used to prepare the solutions. The studied products are commercial and were purchased from pharmaceutical units, and they are presented in Table 2.

Table 1. Reagents used.

\begin{tabular}{ccccc}
\hline Reagent & Purity & CAS & Supplier & Purpose of Usage \\
\hline 1,1-diphenyl-2-picrylylhydrazyl & $\geq 98 \%$ (HPLC) & $1898-66-4$ & Sigma-Aldrich, USA & DPPH method \\
Acetone & p.a. $\geq 99 \%$ & $67-64-1$ & Chempur, Poland & Solvent \\
Boric acid & p.a. $\geq 99 \%$ & $10043-35-3$ & $\begin{array}{c}\text { Micromchim, } \\
\text { Romania }\end{array}$ & Buffer B-R preparation \\
Caftaric acid & $\geq 97.0 \%$ & $67879-58-7$ & Sigma-Aldrich, USA & Dosage \\
(2-Caffeoyl-L-tartaric acid) & & & & \\
\hline
\end{tabular}


Table 1. Cont.

\begin{tabular}{|c|c|c|c|c|}
\hline Reagent & Purity & CAS & Supplier & Purpose of Usage \\
\hline $\begin{array}{c}\text { Cichoric/Chicoric acid } \\
\text { (2,3-Dicaffeoyl-L-tartaric acid) }\end{array}$ & $\geq 95 \%,(\mathrm{HPLC})$ & $6537-80-0$ & Sigma-Aldrich, USA & Dosage \\
\hline $\begin{array}{l}\text { Copper (II) sulphate } \\
\text { pentahydrate }\end{array}$ & $\geq 98 \%$ & 7758-99-8 & Sigma-Aldrich, USA & Interferent \\
\hline D-(+)-glucose monohydrate & $7.0-9.5 \%$ water & $14431-43-7$ & Sigma-Aldrich, USA & Interferent \\
\hline Ethanol & $95 \%$ & $64-17-5$ & Chempur, Poland & Solvent \\
\hline Folin-Ciocalteu reagent & - & $12111-13-6$ & Sigma-Aldrich, USA & $\begin{array}{l}\text { Total content of } \\
\text { polyphenolic } \\
\text { compounds } \\
\text { determination }\end{array}$ \\
\hline Gallic acid & $\geq 98 \%$ (HPLC) & $5995-86-8$ & Sigma-Aldrich, USA & $\begin{array}{c}\text { DPPH antioxidant } \\
\text { activity determination }\end{array}$ \\
\hline Glacial acetic acid & p.a. $\geq 99 \%$ & 64-19-7 & Chempur, Poland & Buffer B-R preparation \\
\hline Chitosan & $\begin{array}{l}\text { Low molecular } \\
\text { weight }\end{array}$ & $9012-76-4$ & Merck, Germany & $\begin{array}{l}\text { Modified electrode } \\
\text { preparation }\end{array}$ \\
\hline L-ascorbic acid & $\geq 99 \%$ & $50-81-7$ & Sigma-Aldrich, USA & $\begin{array}{l}\text { DPPH antioxidant } \\
\text { activity determination }\end{array}$ \\
\hline Magnesium chloride & $\begin{array}{l}\text { Anhydrous, } \\
\geq 98 \%\end{array}$ & $7786-30-3$ & Sigma-Aldrich, USA & Interferent \\
\hline Methanol & $\geq 99 \%$ & $67-56-1$ & Chempur, Poland & Solvent \\
\hline MWCNT & $\leq 100 \%$ & $308068-56-6$ & Sigma-Aldrich, USA & $\begin{array}{l}\text { Modified electrode } \\
\text { preparation }\end{array}$ \\
\hline $\begin{array}{l}\text { Nickel (II) sulphate } \\
\text { hexahydrate }\end{array}$ & $\geq 98 \%$ & 10101-97-0 & Chempur, Poland & Interferent \\
\hline Phenol & $99-100.5 \%$ & $108-95-2$ & Sigma-Aldrich, USA & Interferent \\
\hline Phosphoric acid & $\begin{array}{c}\text { ACS reagent, } \\
\geq 85 \text { wt. } \% \text { in } \\
\mathrm{H}_{2} \mathrm{O}\end{array}$ & $7664-38-2$ & Merck, Germany & Buffer B-R preparation \\
\hline $\begin{array}{l}\text { Potassium ferricyanide, Red } \\
\text { prussiate }\end{array}$ & $\geq 99 \%$ & 13746-66-2 & Merck, Germany & Redox couple \\
\hline $\begin{array}{l}\text { Potassium ferrocyanide, } \\
\text { Yellow prussiate }\end{array}$ & $\geq 98.5 \%$ & 14459-95-1 & Merck, Germany & Redox couple \\
\hline Potassium nitrate & $\geq 99 \%$ & $7757-79-1$ & Merck, Germany & Interferent \\
\hline Resorcinol & $\geq 99 \%$ & $108-46-3$ & Chempur, Poland & Interferent \\
\hline Sodium carbonate & $\begin{array}{l}\text { BioXtra, } \\
\geq 99.0 \%\end{array}$ & 497-1908 & Chempur, Poland & $\begin{array}{l}\text { Total content of } \\
\text { polyphenolic } \\
\text { compounds } \\
\text { determination }\end{array}$ \\
\hline Sodium hydroxide & $\begin{array}{c}\text { BioXtra, } \geq 98.0 \% \\
\text { (acidimetric) } \\
\text { pellets } \\
\text { (anhydrous) }\end{array}$ & $1310-73-2$ & Chempur, Poland & Interferent \\
\hline Sodium chloride & $\geq 99 \%$ & $7647-14-5$ & Sigma-Aldrich, USA & Interferent \\
\hline Tartaric acid & $\geq 99.5 \%$ & $87-69-4$ & Sigma-Aldrich, USA & Interferent \\
\hline Uric acid & $\geq 99 \%$ & 69-93-2 & Chempur, Poland & Interferent \\
\hline
\end{tabular}

HPLC-High-Performance Liquid Chromatography; DPPH-2,2-diphenyl-1-picrylhydrazyl; MWCNT-Multiwall carbon nanotube; B-R-Britton-Robinson; ACS-American Chemical Society; $\mathrm{H}_{2} \mathrm{O}$-water.

Table 2. Pharmaceutical forms with Echinacea.

\begin{tabular}{|c|c|c|c|}
\hline & Manufacturer & Content & Category \\
\hline Capsules $500 \mathrm{mg}$ & $\begin{array}{c}\text { Cosmopharm, Bucharest, } \\
\text { Romania }\end{array}$ & $\begin{array}{l}\text { Concentrated Echinacea extract, } \\
20 \mathrm{mg} \text { polyphenols }\end{array}$ & $\begin{array}{c}\text { Natural } \\
\text { immunostimulant }\end{array}$ \\
\hline Tablets $500 \mathrm{mg}$ & Alevia, Fălticeni, Romania & $\begin{array}{c}\text { Echinacea Purpurea standardized } \\
\text { extract, } 4 \% \text { polyphenols }\end{array}$ & Food supplement \\
\hline Tincture $50 \mathrm{~mL}$ & Dacia Plant, Bod, Romania & $\begin{array}{l}\text { Extract } 1: 3.75 \text { in hydroalcoholic } \\
\text { solution (ethyl alcohol/water- } \\
\text { 35/65 by mass) from aerial parts of } \\
\text { Echinacea purpurea }\end{array}$ & Food supplement \\
\hline
\end{tabular}




\subsection{Solutions and Sample Preparation}

The stock solutions of chicoric acid and caftaric acid, both $25 \mathrm{mmol} / \mathrm{L}$, were prepared in a volumetric mixture of ethanol/water (1:1), and B-R buffer was used for the range of $\mathrm{pH} 2$ to 10, with the buffer consisting of a mixture of 3 acids, as follows: $\mathrm{H}_{3} \mathrm{PO}_{4}, \mathrm{H}_{3} \mathrm{BO}_{3}$ and $\mathrm{CH}_{3} \mathrm{COOH}$, all of them at a concentration of $0.04 \mathrm{~mol} / \mathrm{L}$. pH adjustment was done with $0.01 \mathrm{~mol} / \mathrm{L} \mathrm{NaOH}$.

Extraction of caffeic acid derivatives from the pharmaceutical forms was performed by dissolving/diluting a quantity/volume of powder/solution in a mixture of $20 \mathrm{~mL}$ acetone: water $=60: 40$, under continuous stirring, for $30 \mathrm{~min}$, after which the mixture was centrifuged for $15 \mathrm{~min}$ at $5000 \mathrm{rpm}$. The acetone:water extract was dried in a rotary evaporator at $30^{\circ} \mathrm{C}$, then dissolved in a mixture of methanol:water = 1:1 [21]. The solution obtained is diluted with B-R buffer, obtaining solutions of different concentrations for which the voltammograms are recorded.

Stock solutions were stored at $-5{ }^{\circ} \mathrm{C}$, protected from light. When using the solutions, they are protected by wrapping the voltammetric cell with aluminum foil. Stock solutions can be stored for up to 5 weeks.

All measurements were performed in triplicate.

\subsection{Apparatus}

Voltammetric measurements were performed with an Autolab PGSTAT 128N electrochemical device (Utrecht, Kingdom of the Netherlands), using Nova 2.1.2 software, in a $20 \mathrm{~mL}$ electrochemical cell, equipped with 3 electrodes: reference electrode $\mathrm{Ag} / \mathrm{AgCl}$, auxiliary platinum $(\mathrm{Pt}$ ) electrode wire and working glass carbon electrode (GCE, $3 \mathrm{~mm}$ diameter, Metrohm-Autolab, Switzerland). All of the measurements were performed at room temperature $\left(25 \pm 2{ }^{\circ} \mathrm{C}\right)$. The voltammetric peak intensities were measured using the baseline corresponding to each peak. The $\mathrm{pH}$ of the B-R buffer solution was adjusted with $0.01 \mathrm{M} \mathrm{NaOH}$ solution, using the Brinkmann Metrohm $632 \mathrm{pH}$-meter (Metrohm AG, Herisau, Switzerland) equipped with a combined $\mathrm{pH}$ electrode. Spectrophotometric determinations were performed using T70 ultraviolet-visible (UV-VIS) spectrometer with sequential automatic scanning (PG Instruments Ltd., Leicestershire, United Kingdom), controlled by UVWIN software.

\subsection{Preparation of CNTs in CS}

For the modification of the GCE, a solution of CS 5\% in 2\% acetic acid solution was prepared. CNTs were dispersed in this solution so as to obtain a solution of concentration $1 \mathrm{mg} \mathrm{CNTs} / \mathrm{mL}$, in an ultrasonication bath SONOREX SUPER (Bandelin-Electronic GmbH \& Co. KG, Berlin, Germany), at a temperature of $25 \pm 2{ }^{\circ} \mathrm{C}$, for $30 \mathrm{~min}(1 \mathrm{mg} / \mathrm{mL} \mathrm{CNTs} / \mathrm{CS} 5 \% / \mathrm{GCE})$. Another suspension prepared for electrode modification contained $20 \mathrm{mg} \mathrm{CNTs} / \mathrm{mL} 0.5 \%$ CS solution in $2 \%$ acetic acid solution $(20 \mathrm{mg} / \mathrm{mL} \mathrm{CNTs} / \mathrm{CS} 0.5 \% / \mathrm{GCE})[32,33]$. CS has the role of fixing the strong electroactive material of CNTs to the surface of the glassy carbon electrode.

\subsection{Preparation of Modified GCE}

Two types of methods (physical and chemical) were used to clean the electrode for every work phase. The physical treatment consisted of polishing the electrode manually, using alumina power $(\varnothing=0.3$ micron), for one minute, then rinsing it using deionized water. The chemical treatment consisted of sonicating the electrode in $6 \mathrm{M} \mathrm{HCl}$ solution for three minutes and rinsing it using deionized water, followed by sonication in ethanol for three minutes, then rinsing with deionized water. The modification of the glass carbon electrode was performed by depositing $5 \mu \mathrm{L}$ suspension of CNTs in CS, followed by air drying. 


\subsection{Determination of the Total Polyphenol Content}

\subsubsection{Differential Pulse Voltammetry}

To calculate the amount of caffeic acid and catechins in pharmaceutical forms, the following steps were taken: knowing the current intensity for the mixture of standard solution of caffeic and chicoric acids, the current intensities for caffeic acid (approximately $0.203 \pm 0.007 \mathrm{~V}$ ), mixture of caffeic acid + chicoric (approximately $0.520 \pm 0.024 \mathrm{~V}$ ) and catechins (approximately $0.690 \pm 0.005 \mathrm{~V}$ ) were combined, and a proportionality calculation determined the respective compounds. These calculations were performed due to the fact that in Echinacea extracts, there are polyphenols that could be attributed to caffeic acid and catechins.

\subsubsection{Spectrophotometry}

The total content of polyphenolic compounds in Echinacea purpurea extracts was colorimetrically determined, using Folin-Ciocalteu reagent and gallic acid (GA) [34]. The selection of GA as a standard was based on its availability to be stable in the pure substance state. Folin-Ciocalteu reagent is used for colorimetric analysis of phenolic and polyphenolic antioxidants. Basically, a sample of $0.2 \mathrm{~mL}$ of Echinacea purpurea extract was added to a test tube and mixed with $2 \mathrm{~mL}$ of Folin-Ciocalteu reagent; after $5 \mathrm{~min}$ of reaction, $1.8 \mathrm{~mL}$ of sodium carbonate $(7.5 \%)$ was added. The absorbance was measured at $750 \mathrm{~nm}$, using the UV-VIS spectrophotometer. The curve was established for analysis using GA. The polyphenolic content was determined using the standard GA calibration curve and expressed in mg of GA equivalents (GAE).

\subsection{Antioxidant Activity Determination}

\subsubsection{Cyclic Voltammetry}

To draw a calibration line, a $10^{-2} \mathrm{M}$ ascorbic acid (AA) solution was prepared and was used to record the differential pulse voltammograms for 7 AA solutions (with concentrations between 0.25 and $4.59 \mathrm{mM}$ ) in B-R buffer. Similarly, a $10^{-2} \mathrm{M} \mathrm{GA}$ solution was prepared for tracing a calibration line that was used to record differential pulse voltammograms for 10 GA solutions (with concentrations between 0.25 and $6.55 \mathrm{mM}$ ) in B-R buffer.

\subsubsection{DPPH Method}

The antioxidant activity of the standardized Echinacea purpurea extract was measured with a stable free radical 1,1-diphenyl-2-picrilhydrazyl (DPPH) according to the Briefly method [35]. The method involves reducing the DPPH staining (from purple to yellow) in the presence of a phenolic antioxidant $(\mathrm{FeOH})$, in methanolic solution, according to the reactions:

$$
\begin{gathered}
\mathrm{DPPH}+\mathrm{FeOH} \rightarrow \mathrm{DPPH}-\mathrm{H}+\mathrm{FeO} \cdot \\
\mathrm{DPPH}-\mathrm{H}+\mathrm{FeO} \rightarrow \text { Degradation/oxidation products }
\end{gathered}
$$

The DPPH method is based on the reaction with electron donors or hydrogen radicals $(\mathrm{H} \cdot)$ producing antioxidant compounds. It was found that the ability to capture free radicals from extracts increases with increasing concentrations of antioxidants. The reduction in DPPH is directly proportional to the amount of antioxidant present in the reaction mixture.

Each analyzed extract $(0.20 \mathrm{~mL}$ of the previously prepared solutions) was mixed with $2.80 \mathrm{~mL}$ $0.1 \mathrm{mM}$ of freshly prepared solution of DPPH radical in methanol. The mixture was kept in the dark for $15 \mathrm{~min}$ at $37^{\circ} \mathrm{C}$, after which its absorbance was read at $517 \mathrm{~nm}$ in $1 \mathrm{~cm}$ quartz cuvettes, compared to a solution of DPPH radical in methanol. Antioxidant activity was expressed as $\mathrm{mM}$ equivalents of AA per g dry weight (DW), using the calibration curve constructed with $0.05,0.1,0.2,0.3,0.4$ and 
$0.5 \mathrm{mM}$ AA dissolved in methanol and with the same concentrations of GA $(0.05,0.1,0.2,0.3,0.4$ and $0.5 \mathrm{mM}$ ) also dissolved in methanol.

\section{Results}

\subsection{Electrochemical Characterization of Electrodes by Cyclic Voltammetry}

In order to characterize the modified electrode, cyclic voltammetry was used for a redox probe, consisting of 2 electroactive species $\mathrm{K}_{3}\left[\mathrm{Fe}(\mathrm{CN})_{6}\right] / \mathrm{K}_{4}\left[\mathrm{Fe}(\mathrm{CN})_{6}\right]$, in the form of a $10 \mathrm{mM}$ solution in B-R buffer. Scanning voltammetry was performed in the range -0.500 to $0.800 \mathrm{~V}$ in anodic direction, returning to the initial point in the cathodic direction with a scanning speed of $0.1 \mathrm{~V} / \mathrm{s}$ (Figure 2).

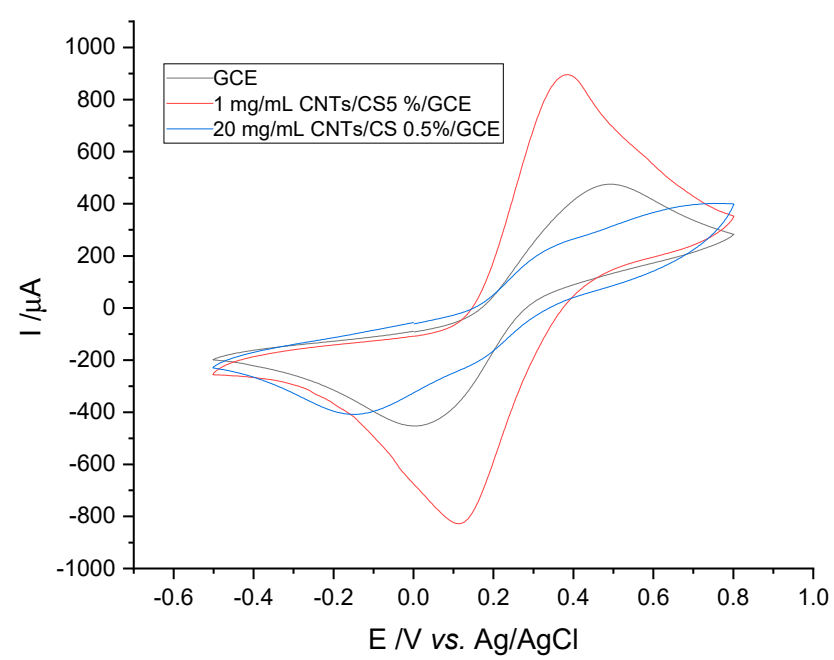

Figure 2. Cyclic voltammograms of electrodes in $\mathrm{K}_{3}\left[\mathrm{Fe}(\mathrm{CN})_{6}\right] / \mathrm{K}_{4}\left[\mathrm{Fe}(\mathrm{CN})_{6}\right] 10 \mathrm{mM}$ solution in Britton-Robinson (B-R) buffer ( $\mathrm{pH}$ 3), $0.100 \mathrm{~V} / \mathrm{s}$ scan rate.

An intensity of the oxidation peak for $1 \mathrm{mg} / \mathrm{mL}$ CNTs/CS 5\%/GCE-modified electrode can be observed at $803 \mu \mathrm{A}$, for GCE, at $349 \mu \mathrm{A}$, and for $20 \mathrm{mg} / \mathrm{mL}$ CNTs/CS $0.5 \% / G C E$ electrode, at $114 \mu \mathrm{A}$. This indicates a clearly superior electroactive surface of $1 \mathrm{mg} / \mathrm{mL} \mathrm{CNTs} / \mathrm{CS} 5 \% / G C E$-modified electrode compared to the other two electrodes. It is a fact also confirmed by the calculation of the electroactive surface with the Randels-Sevcik Equation (Equation (1)) [36], for all three electrodes investigated in the cyclic voltammograms recorded in the redox probe $\mathrm{K}_{3}\left[\mathrm{Fe}(\mathrm{CN})_{6}\right] / \mathrm{K}_{4}\left[\mathrm{Fe}(\mathrm{CN})_{6}\right] 10 \mathrm{mM}$, in B-R buffer, as follows:

$$
I_{p}=2.69 \times 10^{5} \times n^{3 / 2} A D^{1 / 2} v^{1 / 2} C
$$

where $I_{p}$ is current intensity (A), $n$ is number of electrons transferred (usually 1 ), $A$ is the electroactive surface of the electrode $\left(\mathrm{cm}^{2}\right), D$ is the diffusion coefficient $\left(\mathrm{cm}^{2} / \mathrm{s}\right), C$ is concentration $(\mathrm{mol} / \mathrm{mL})$ and $v$ is scan speed $(\mathrm{V} / \mathrm{s})$.

For the anodic peak, the largest electroactive surface is at the electrode $1 \mathrm{mg} / \mathrm{mL}$ CNTs/CS $5 \% / G C E$ $\left(0.342 \mathrm{~cm}^{2}\right)$ and the smallest at the electrode $20 \mathrm{mg} / \mathrm{mL} \mathrm{CNTs} / \mathrm{GCE}\left(0.048 \mathrm{~cm}^{2}\right)$, increasing by 7.125 times. In these calculations, the unmodified GCE is intermediate $\left(0.149 \mathrm{~cm}^{2}\right)$ in terms of signal. Regarding the cathodic peak, the signal difference is no longer very different due to the higher cathodic peak of the electrode $20 \mathrm{mg} / \mathrm{mL} \mathrm{CNTs} / \mathrm{CS} 0.5 \% / G C E$. In the following, the best performing electrode $1 \mathrm{mg} / \mathrm{mL}$ CNTs/CS 5\%/GCE will be denoted as CNTs/CS/GCE.

\subsubsection{Influence of Scanning Speed on the Intensity of the Anodic/Cathodic Peak}

Cyclic voltammograms were recorded in the range -0.500 to $0.800 \mathrm{~V}$ for a $10 \mathrm{mM}$ chicoric acid solution, at different scanning speeds $(0.010,0.025,0.050,0.075,0.100,0.150,0.200$ and $0.300 \mathrm{~V} / \mathrm{s})$, in solution of B-R buffer (Figure 3A). As the scanning speed intensifies, voltammograms describe 
a sharp increase in oxidation peaks, and the potential of these peaks shifts to higher values. Also, the maximum potentials moved to increased $(0.610 \pm 0.060 \mathrm{~V})$ and decreased $(0.435 \pm 0.055 \mathrm{~V})$ values for the oxidation and reduction processes. The intensities of oxidation and reduction currents also vary in direct proportion with the square root of the scanning speed (Figure 3B). This is demonstrated by linear regression equations:

$$
\begin{gathered}
\mathrm{I}_{\mathrm{pa}}(\mu \mathrm{A})=-28.52645+0.0076 \times \mathrm{v}^{1 / 2}(\mathrm{~V} / \mathrm{s}) \\
\mathrm{I}_{\mathrm{pc}}(\mu \mathrm{A})=32.45163-0.0081 \times \mathrm{v}^{1 / 2}(\mathrm{~V} / \mathrm{s})
\end{gathered}
$$

with a correlation coefficient of 0.98191 and 0.98067 , which indicates that the electrochemical reaction is a controlled diffusion process that occurs in all solutions and is due to unequal local concentrations of reagents.

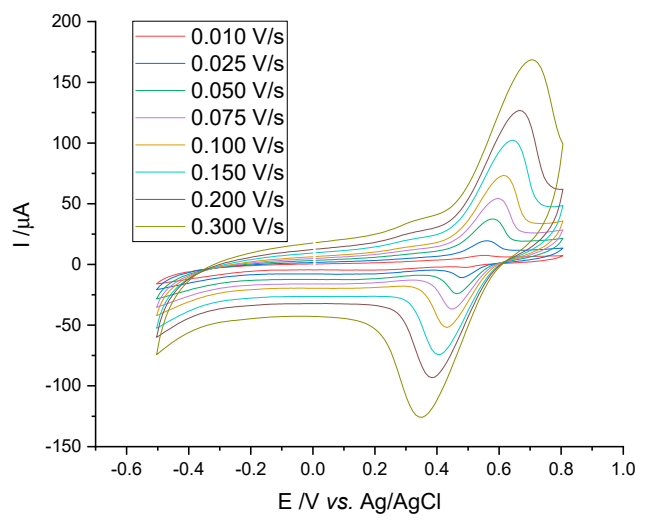

A

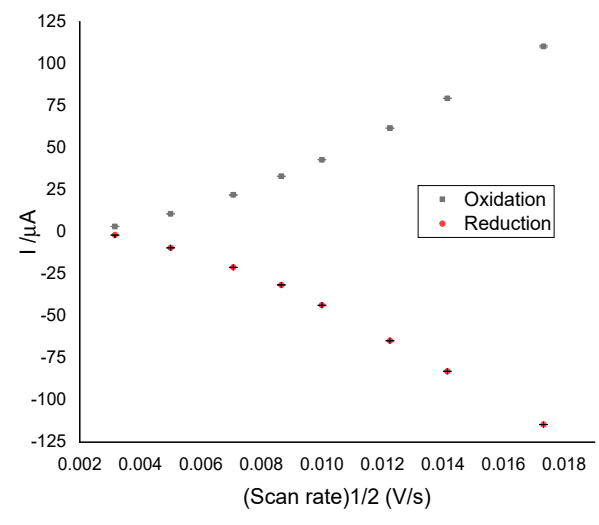

B

Figure 3. (A) Cyclic voltammograms for a $10 \mathrm{mM}$ chicoric acid solution with scan speeds of $0.010,0.025$, $0.050,0.075,0.100,0.150,0.200$ and $0.300 \mathrm{~V} / \mathrm{s}$, in B-R buffer $(\mathrm{pH}=3)$ with modified electrode containing $20 \mathrm{mg} \mathrm{CNTs} / \mathrm{mL} 0.5 \% \mathrm{CS}$ solution in $2 \%$ acetic acid solution ( $20 \mathrm{mg} / \mathrm{mL} \mathrm{CNTs} / \mathrm{CS} 0.5 \% / \mathrm{GCE}$ ) denoted CNTs/CS/GCE. (B) The linearity between the peak current (Ip) and the square root of the scan rate $\mathrm{v}^{1 / 2}$.

At a slow scanning speed, the diffusion layer will develop at a greater distance from the electroactive surface of the sensor compared to a rapid scanning of the potential. Electron flux at the electrode is lower at slow scanning speeds versus faster scanning speeds.

\subsubsection{Optimization of the $\mathrm{pH}$ Value}

The solution with $10 \mathrm{mM}$ concentration of chicoric acid in B-R buffer, at different $\mathrm{pH}$ values, was tested. Differential pulse voltammograms recorded in the range 0 to $1.0 \mathrm{~V}$ are shown in Figure $4 \mathrm{~A}$. A high current intensity is observed for a solution with $\mathrm{pH}=3$ intensity that decreases with increasing $\mathrm{pH}$ of the B-R buffer. Moreover, the shift of the oxidation peak to lower potential values can be observed simultaneously with the increase of the $\mathrm{pH}$ values of the B- $\mathrm{R}$ solution (except the $\mathrm{pH}=2 \mathrm{~B}-\mathrm{R}$ solution) (Figure 4B).

\subsubsection{Calibration Iines}

The calibration lines were determined by differential pulse voltammetry in the range 0.0 to $1.0 \mathrm{~V}$. Stock solutions of caftaric and chicoric acids were prepared, both with a concentration of $25 \mathrm{mM}$, in a mixture of ethanol:water (1:1). Aliquots of acids were successively added over $10 \mathrm{~mL}$ of B-R electrolyte solution. The measurements were recorded with the same system of three electrodes: $\mathrm{Ag} / \mathrm{AgCl}$ electrode (reference electrode), platinum wire electrode (counter electrode) and CNTs/CS/GCE (working electrode). Differential pulse voltammograms are shown in Figure 5A,B. The calibration diagrams resulted in arranging the peak amplitude against the standard solutions concentration. 
The peak current amplitude against concentration dependence was registered in the concentration interval of the analyte (Figure 5C,D).

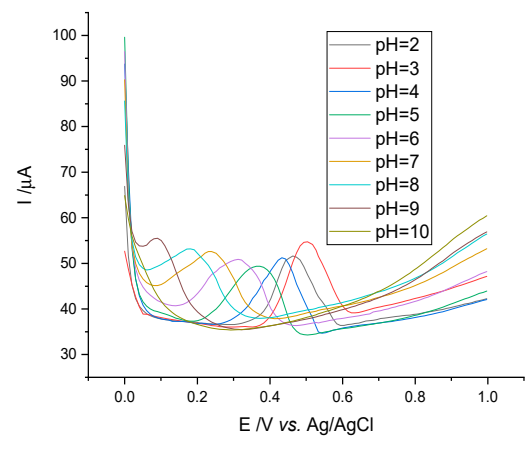

A

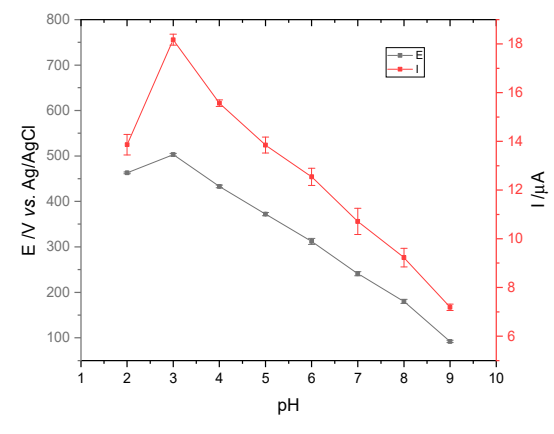

B

Figure 4. (A) Differential pulse voltammograms for a $10 \mathrm{mM}$ chicoric acid solution in Britton-Robinson buffer at different $\mathrm{pH}$ values. (B) Plot of anodic peak potential and peak current vs. $\mathrm{pH}$.

The two calibration lines are expressed through the following equations:

$$
\begin{aligned}
& \mathrm{I}(\mu \mathrm{A})=-0.96521+6.8482^{\circ} \mathrm{C}(\mathrm{mM}) \\
& \mathrm{I}(\mu \mathrm{A})=24.85987+1.0636{ }^{\circ} \mathrm{C}(\mathrm{mM})
\end{aligned}
$$

having values of $R=0.99500$ and $R=0.98484$, respectively. The amplitude of the peak current was considered as the interval between the baseline and the maximum value of the current.

In Figure $5 \mathrm{~A}, \mathrm{~B}$, the oxidation peak of caftaric acid occurs at $0.505 \pm 0.002 \mathrm{~V}$, and that of chicoric acid at $0.515 \pm 0.001 \mathrm{~V}$.
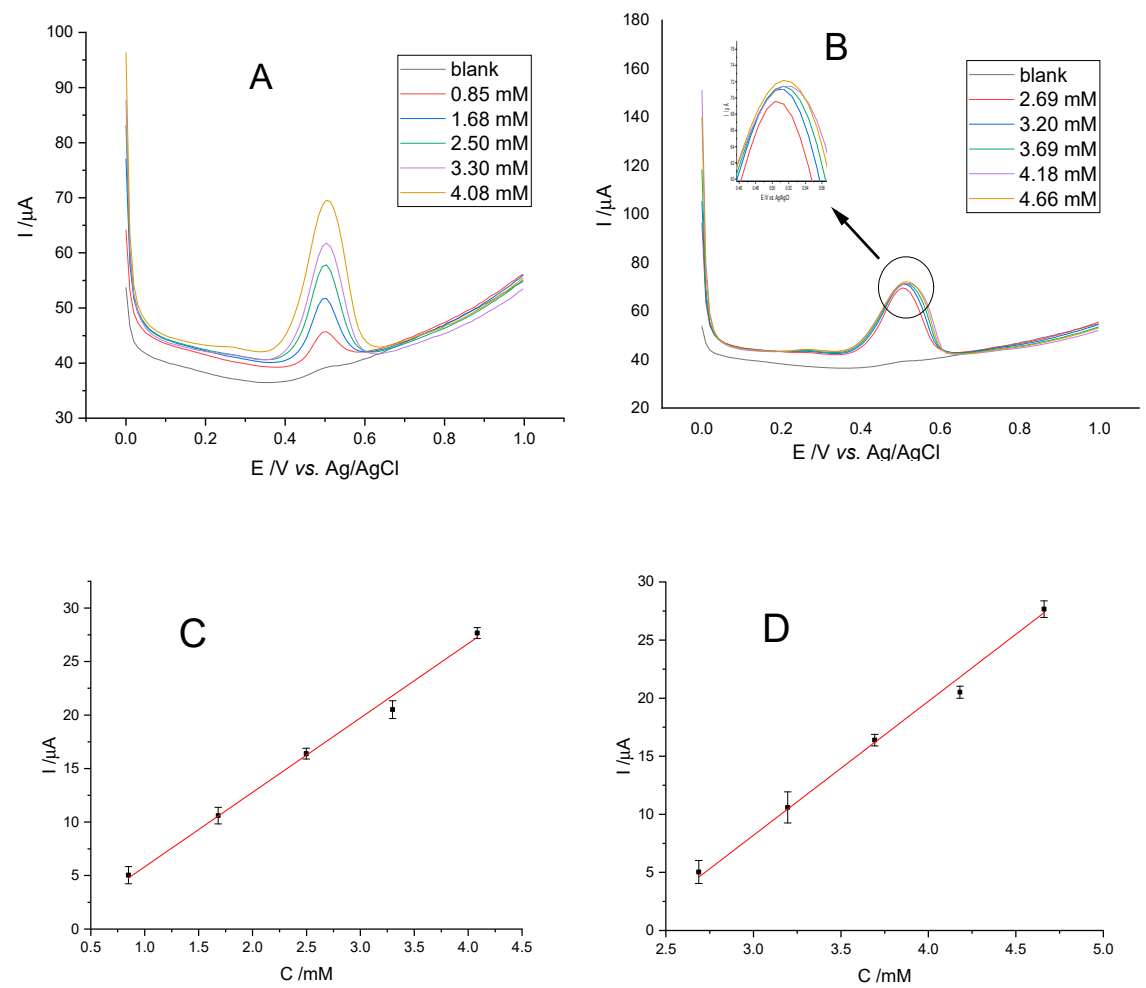

Figure 5. Differential pulse voltammograms for (A) caftaric acid: $0.85,1.68,2.50,3.30$ and $4.08 \mathrm{mM}$, (B) chicoric acid: $2.69,3.20,3.69,4.18$ and $4.66 \mathrm{mM}$ in Britton-Robinson buffer $(\mathrm{pH}=3)$, (C) calibration curve for A, (D) calibration curve for B. 
The amplitude of the peak current was considered as the interval between the baseline and the maximum value of the current. Limits of detection (LOD) were calculated using the $3 \sigma / \mathrm{S}$ ratio, ( $\sigma$-standard deviation of the response, $\mathrm{S}$ - slope of the calibration curve) and limits of quantification (LOQ) were specified using the $10 \sigma / \mathrm{S}$ ratio, and their values are summarized in Table 3.

Table 3. Detection and quantification limits for caftaric and chicoric acids.

\begin{tabular}{cccc}
\hline Acid & Linearity Range & Limit of Detection $(\mathbf{m M})$ & Limit of Quantification \\
\hline Caftaric & $0.850-4.084$ & 0.283 & 0.850 \\
Chicoric & $2.691-4.661$ & 0.897 & 2.691 \\
\hline
\end{tabular}

\subsubsection{Electrode Stability}

The reproducibility of the modified electrode with CNTs was investigated. Thus, differential pulse voltammograms were recorded for a $10 \mathrm{mM}$ chicoric acid solution for two consecutive weeks (Figure 6). The standard deviation of the oxidation peaks measured 3 times for each day was $2.69 \%$, which means that the CNTs/CS/GCE electrode has a good reproducibility.

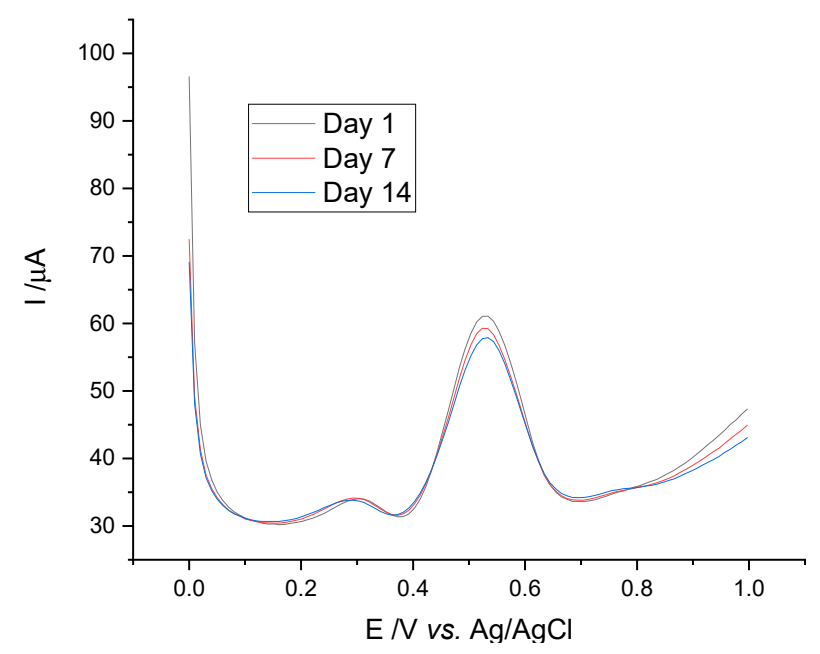

Figure 6. Differential pulse voltammograms for a $10 \mathrm{mM}$ chicoric acid solution measured on days 1, 7 and 14 using the CNTs/CS/GCE electrode in Britton-Robinson buffer $(\mathrm{pH}=3)$.

\subsubsection{Interference Studies}

For a solution containing both caftaric and chicoric acids, in concentrations of 6.40 and $5.55 \mathrm{mM}$, the influence of interferences was studied. Organic substances (such as resorcinol, glucose, uric acid, phenol and tartaric acid) with a concentration of $10 \mathrm{mM}$ in solution, brought an increase in the intensity of the oxidation peaks corresponding to caftaric acid and caffeic acid, with a maximum of $3.2 \%$. Inorganic ions (i.e., $\mathrm{Na}^{+}, \mathrm{K}^{+}, \mathrm{Mg}^{2+}, \mathrm{Ni}^{2+}, \mathrm{Cu}^{2+}, \mathrm{Cl}^{-}, \mathrm{NO}_{3}{ }^{-}$and $\mathrm{SO}_{4}{ }^{2-}$, Table 1), having concentrations of $100 \mathrm{mM}$ in the solution of caftaric acid and chicoric acid, also did not significantly alter the signal of the oxidation peak. So, the CNTs/CS/GCE electrode had a good selectivity in determining the two acids (caftaric and chicoric).

\subsection{Voltammetric Study of Echinacea Purpurea in Pharmaceutical Forms}

Differential pulse voltammograms were recorded in the same range of 0.0 to $1.0 \mathrm{~V}$ in B-R buffer.

Figure 7 shows the differential pulse voltammograms for a solution of caftaric acid and chicoric acid (concentration of 6.40 and $5.55 \mathrm{mM}$ ) along with 3 other solutions of Echinacea purpurea extract $3.00 \mathrm{mg} / \mathrm{mL}$ from capsules/tablets/tincture in B-R buffer. The presence of strong oxidation peaks at $0.515 \pm 0.025 \mathrm{~V}$, due to the oxidation of 3,4-dihydroxyl substituents (caftaric acid and chicoric acid), is noted. 


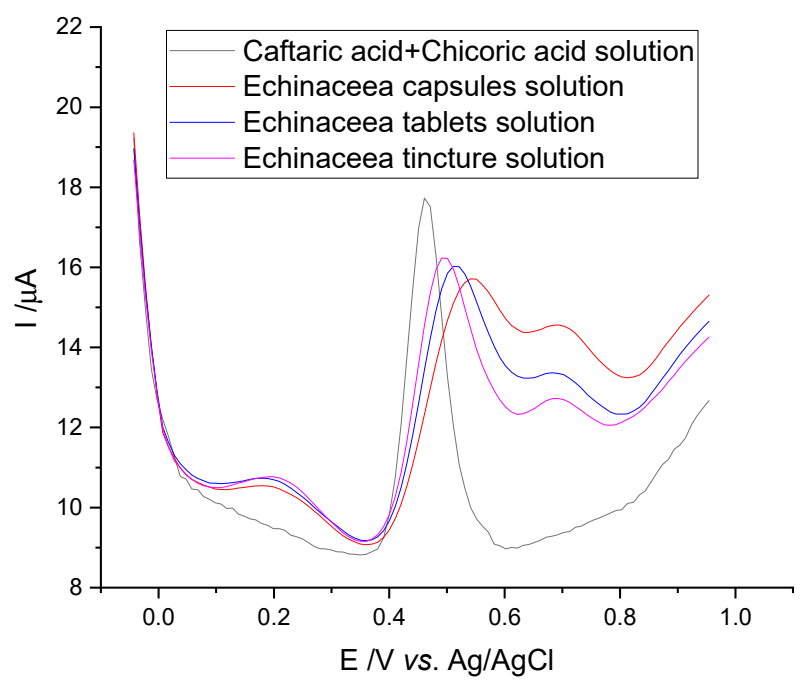

Figure 7. Differential pulse voltammograms for caftaric acid solution $(6.40 \mathrm{mM})$ and chicoric acid (5.55 mM), for Echinacea purpurea extracts (capsules, tablets, tincture) $3 \mathrm{mg} / \mathrm{mL}$ in Britton-Robinson buffer ( $\mathrm{pH} 3)$.

The presence of the other two oxidation peaks from $0.209 \pm 0.002 \mathrm{~V}$ and $0.697 \pm 0.005 \mathrm{~V}$ of the studied pharmaceutical forms can be attributed to caffeic acid or quercetin [21] respectively, to malvidin-3-glucoside, catechin or chlorogenic acid [37,38]. Amounts of polyphenols have similar values to those found by Oniszczuk et al. [39].

By correlating the oxidation peaks for both caftaric and chicoric acids with the current intensities for the oxidation peaks of the analyzed pharmaceutical forms, the quantities of polyphenols existing in the Echinacea extracts were obtained. The polyphenolic content was determined by the spectrophotometric method, and the standard GA calibration curve (expressed in GAE) was used. The values obtained are specified in Table 4.

Table 4. The amounts of acids present in the analyzed pharmaceutical forms with Echinacea.

\begin{tabular}{|c|c|c|c|c|c|c|}
\hline \multirow[b]{2}{*}{$\begin{array}{l}\text { Pharm. } \\
\text { Form }\end{array}$} & \multicolumn{5}{|c|}{ Voltammetry } & \multirow{2}{*}{$\begin{array}{c}\text { Spectrophotometry } \\
\text { Total Content of } \\
\text { Polyphenols Found } \\
\text { mg GAE/500 mg } \\
\text { Powder }\end{array}$} \\
\hline & $\begin{array}{c}\text { Total } \\
\text { Phenolic } \\
\text { Derivatives } \\
\text { Theoretically }\end{array}$ & Caffeic Acid & $\begin{array}{c}\text { Caftaric + } \\
\text { Cichoric } \\
\text { Acids }\end{array}$ & Catechins & $\begin{array}{c}\text { Total Content } \\
\text { of Polyphenols } \\
\text { Found }\end{array}$ & \\
\hline \multicolumn{7}{|c|}{$\mathrm{mg} / 500 \mathrm{mg}$ Powder } \\
\hline Capsules & 20 & $2.006 \pm 0.214^{*}$ & $16.129 \pm 0.159$ & $1.366 \pm 0.583$ & $19.501 \pm 0.483$ & $2.638 \pm 0.258$ \\
\hline Tablets & 20 & $1.958 \pm 0.348$ & $16.222 \pm 0.291$ & $1.622 \pm 0.794$ & $19.802 \pm 0.678$ & $2.682 \pm 0.592$ \\
\hline Tincture & 30 & $2.161 \pm 0.287$ & $22.701 \pm 0127$ & $3.866 \pm 0.927$ & $28.728 \pm 0.826$ & $3.890 \pm 0.156$ \\
\hline
\end{tabular}

\subsection{Antioxidant Activity}

The differential pulse voltammograms for the gallic and ascorbic polyphenolic acids standards are shown in Figure 8A,B. Characteristic irreversible oxidation processes were registered for both compounds, similar to those observed for other antioxidant compounds (with one anodic peak Epa $=0.515 \pm 0.035 \mathrm{~V}$ for ascorbic acid [40-43], and two anodic peaks $\mathrm{E}(\mathrm{I}) \mathrm{pa}=0.370 \pm 0.040 \mathrm{~V}$, $\mathrm{E}(\mathrm{II}) \mathrm{pa}=0.550 \pm 0.030 \mathrm{~V}$ for gallic acid $[44,45])$.

The equations of the calibration lines (Figure 8C,D) of AA (Equation (6)) and GA (Equation (7)) are:

$$
\begin{aligned}
\mathrm{I}(\mu \mathrm{A}) & =21.42588+1376.17861^{\circ} \mathrm{C}(\mathrm{mol} / \mathrm{L}) ; \mathrm{R}=0.99806 \\
\mathrm{I}(\mu \mathrm{A}) & =1.12068+2708.14749{ }^{\circ} \mathrm{C}(\mathrm{mol} / \mathrm{L}) ; \mathrm{R}=0.99827
\end{aligned}
$$


Using the equations of the calibration lines for the two acids, the equivalent concentration was calculated for the three pharmaceutical forms analyzed in relation to the respective acids. Thus, the antioxidant capacity of Echinacea extract powder, relative to AA and GA, is shown in Table 5.
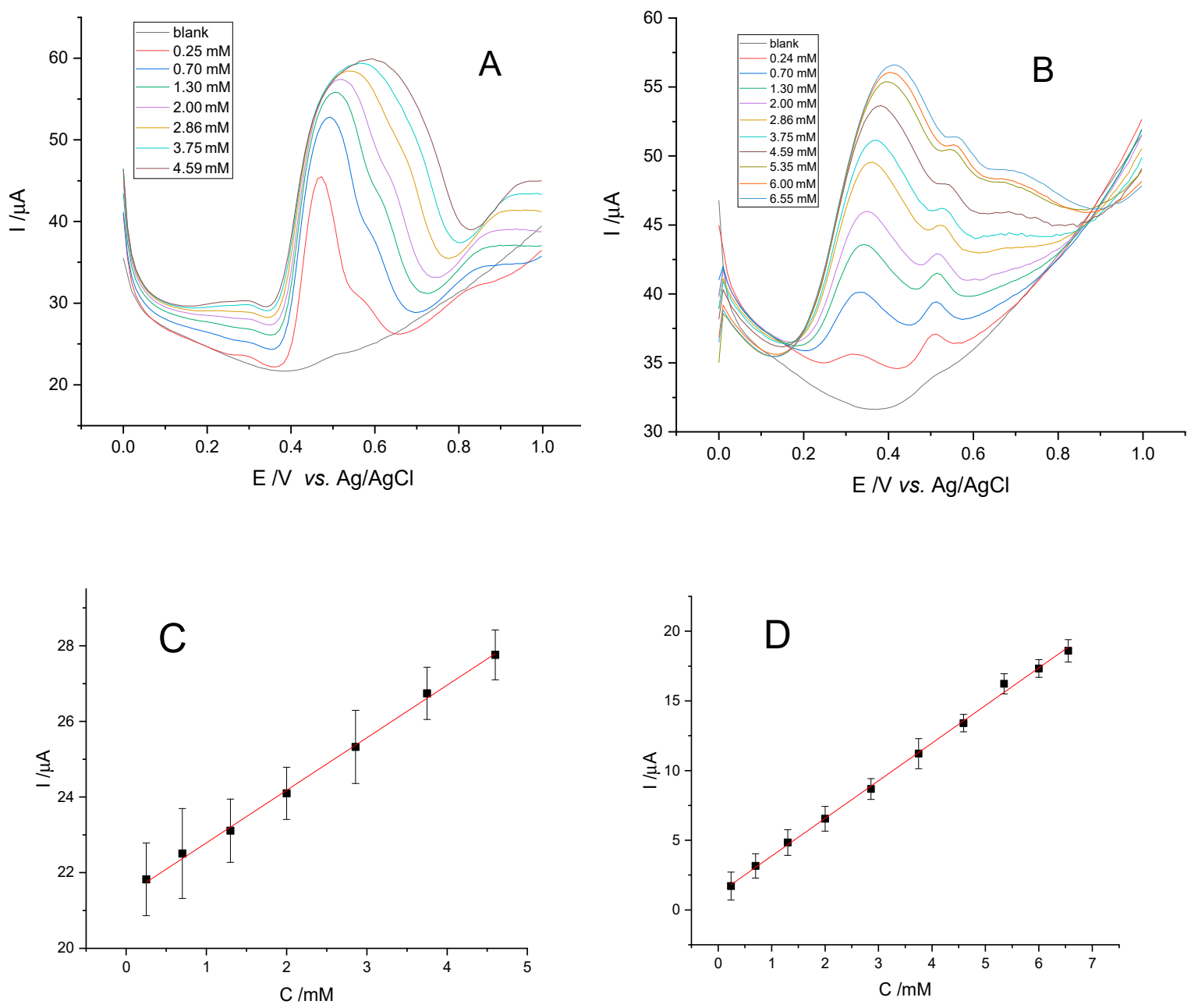

Figure 8. Differential pulse voltammograms for (A) ascorbic acid solutions 0.25, 0.70, 1.30, 2.00, 2.86, 3.75 and $4.59 \mathrm{mM}$, and (B) gallic acid 0.24, 0.70, 1.30, 2.00, 2.86, 3.75, 4.59, 5.35, 6.00 and $6.55 \mathrm{mM}$, in Britton-Robinson buffer ( $\mathrm{pH}=3$ ). (C) Calibration curve for A, (D) calibration curve for B.

Table 5. Antioxidant capacity equivalent to ascorbic/gallic acid (AA/GA).

\begin{tabular}{ccccc}
\hline \multirow{2}{*}{ Pharmaceutical Form } & \multicolumn{3}{c}{ Antioxidant Activity, mg acid/g Extract } \\
\cline { 2 - 5 } & \multicolumn{2}{c}{ Voltammetry } & Spectrophotometry \\
\cline { 2 - 5 } & AA & GA & AA & GA \\
\hline Capsules & $6.125 \pm 0.428^{\text {a }}$ & $0.952 \pm 0.819$ & $8.917 \pm 0.482$ & $3.009 \pm 0.294$ \\
Tablets & $6.354 \pm 0.181$ & $1.133 \pm 0.483$ & $9.457 \pm 0.824$ & $3.191 \pm 0.326$ \\
Tincture & $6.722 \pm 0.537$ & $1.245 \pm 0.724$ & $9.826 \pm 0.624$ & $3.457 \pm 0.753$ \\
\hline
\end{tabular}

a SD: standard deviation for 3 determinations.

In the case of determination by the DPPH method, the calibration curves for AA and GA are linear (with a correlation coefficient $>0.99$ ), which indicates a good correspondence between the concentration of the analyzed solutions and the respective absorbance: $\mathrm{A}_{\mathrm{AA}}=0.02079+1.0937 \mathrm{C}(\mathrm{mM}), \mathrm{R}=0.99663$ and $\mathrm{R}^{2}=0.99579$, and $\mathrm{A}_{\mathrm{GA}}=0.10301+1.26575 \mathrm{C}(\mathrm{mM}), \mathrm{R}=0.99290$ and $\mathrm{R}^{2}=0.99112$, as it is also shown in Figure 9. 


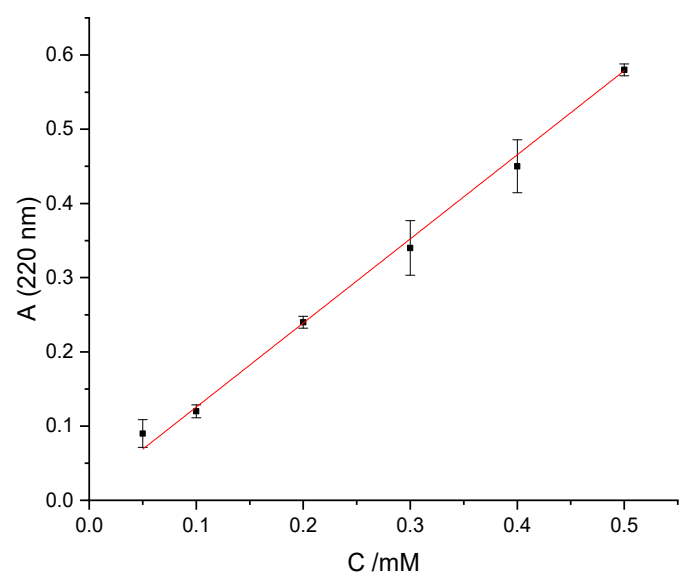

A

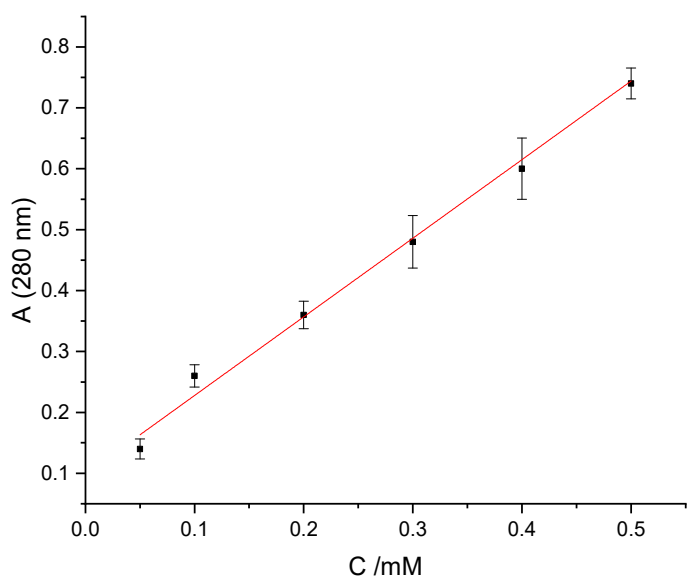

B

Figure 9. Calibration lines for (A) ascorbic acid and (B) gallic acid.

The possible association between the total polyphenol content and the antioxidant activity was tested, and it resulted in a direct, positive and strong association in intensity, regardless of the report $\left(r=0.93542, R^{2}=0.87502, p=0.23\right.$-equivalent to AA; $r=0.880797, R^{2}=0.65282, p=0.4$-equivalent to GA).

\section{Discussion}

The determination of total content of polyphenols and antioxidant activity of natural pharmaceutical products is a difficult goal, being both selective and sensitive at the same time. For this purpose, simple and fast techniques are needed. Our research presented a sensitive electrochemical method of determination (both for the total polyphenols content and for the antioxidant activity of Echinacea purpurea extracts), benefiting from a newly manufactured glassy carbon electrode, modified with CNTs. CNTs are the most relevant representatives of the nanomaterials that are used in the manufacturing process of the electrochemical sensors, having high performance. Multiwalled CNTs are usually selected, taking into account their many advantages (high electrocatalytic activity and rapid electron transfer rate).

The structure of the caffeic acid derivatives that have ortho-dihydroxyl groups is highly connected to their reaction of oxidation [46]. The oxidation process of the catechol moiety implies a two-electron transfer that takes place stepwise through one-electron processes, succeeded by a permanent/unchangeable chemical reaction for every stage to yield an o-quinone end-product [47]. Accordingly, at the glassy carbon electrode (GCE) surface, the Echinacea extracts, chicoric or caftaric acid, that have comparable moiety of caffeic acid, will be oxidized. The modification of glassy carbon electrodes increases the redox peak current; also, it could be used with higher sensitivity.

For the electrode characterization, a redox system was used, with 2 electroactive species, which offers the advantage of showing a peak of oxidation, and respectively, a peak of reduction, regardless of the scanning direction of the cyclic voltammetry. Thus, if scanned to positive potentials, the oxidation peak of $\mathrm{K}_{4}\left[\mathrm{Fe}(\mathrm{CN})_{6}\right]$ will be observed, and if the scanning direction is changed to negative potentials, the reduction peak of $\mathrm{K}_{3}\left[\mathrm{Fe}(\mathrm{CN})_{6}\right]$ will be observed. If only $\mathrm{K}_{3}\left[\mathrm{Fe}(\mathrm{CN})_{6}\right]$ is used, under conditions of scanning to positive potentials, no signal will be observed in the anodic half-cycle, but a $\mathrm{K}_{3}\left[\mathrm{Fe}(\mathrm{CN})_{6}\right]$ reduction signal will appear in the cathodic half-cycle as well as the oxidation of $\mathrm{K}_{4}\left[\mathrm{Fe}(\mathrm{CN})_{6}\right]$ generated in the next anodic half-cycle. The results indicated that the tested electrode has a higher sensitivity than the other two electrodes used and can be used to determine the number of polyphenols and antioxidant activity.

In cyclic voltammetry, Ip depends on several factors: scanning speed, concentration of electroactive species, diffusion properties of electroactive species at the electrode surface, etc. Based on these 
considerations, and the first two factors listed above being identical for the three electrodes used, it is obvious that a net higher value of Ip for the electrode CNTs/CS/GCE is due to a very good electroactive surface compared to the other two electrodes used. If referring to the two modified electrodes, it can be stated that a smaller amount of added CS cannot fix a large quantity of CNTs to the electrode surface (based on the Ip values corresponding to the two modified electrodes).

Voltammetry studies have shown the presence of oxidation peaks at $0.505 \mathrm{~V}$ for caftaric acid and $0.515 \mathrm{~V}$ for chicoric acid, and they increase in direct proportion with the increase of the acid concentration in the range of $0.85-4.08 \mathrm{mM}$, and respectively in the range of 2.69-4.66 $\mathrm{mM}$ (Figure 5). These peaks are due to the oxidation of the $-\mathrm{OH}$ groups to the quinoline form, oxidation that consumes 2 electrons and 2 protons to form o-quinone for the studied acids [48].

Oxidation peaks in voltammograms demonstrate the existence of electroactive phenolic species in the extract and can be used to determine the total polyphenol content. This finding confirms that, based on the current intensities, the two acids mentioned above are the main polyphenols existing in the extract, because similar results were obtained for the standard phenolic compounds of caftaric and chicoric acid. Oxidation potentials that occur at $0.505 \mathrm{~V}$ (Figure 7) and $0.515 \mathrm{~V}$ (Figure 7) for both acids have close values that cannot be split by the electrode used. It should be noted that the shift of the oxidation peak towards more negative and positive potential values for the analyzed forms is due to the presence of other polyphenolic compounds in the studied extracts.

The antioxidant activity was examined by comparing and reporting two substances with strong antioxidant effects: ascorbic acid and gallic acid. Of the three pharmaceutical forms studied, Echinacea tincture had the highest antioxidant capacity (relative to ascorbic acid and gallic acid) and the total amount of polyphenols ( $28.72 \mathrm{mg} /$ equivalent of $500 \mathrm{mg}$ powder). Echinacea capsules had the lowest antioxidant capacity, but also the lowest total amount of polyphenols $(19.50 \mathrm{mg} / 500 \mathrm{mg}$ powder). Similarly, the tablets had approximately the same values of polyphenols content $(19.80 \mathrm{mg} / 500 \mathrm{mg}$ powder), and also antioxidant capacity. The positive association between total polyphenol content and antioxidant activity demonstrates the importance of polyphenolic compounds that contribute to the antioxidant activity of echinacea extracts, but also to the total antioxidant effect. These results are consistent with other studies that evaluated the antioxidant activity of Echinacea purpurea by spectrophotometric or electrochemical methods [21,49].

\section{Conclusions}

The results of this study indicate that the pulse-differential cyclic voltammetry represents a rapid, simple and sensitive technique to establish the entire polyphenolic amount and the antioxidant activity of the E. purpurea extracts. The modified $1 \mathrm{mg} / \mathrm{mL}$ CNTs/CS 5\%/GCE electrode has superior properties compared to the other two (the unmodified and $20 \mathrm{mg} / \mathrm{mL}$ CNTs/CS 0.5\%/GCE-modified) electrodes used and can be operated with to determine the polyphenol content and antioxidant capacity of natural extracts, supplements and foods. Due to the very good correlation between the antioxidant action obtained and the total polyphenolic content, it is considered that the antioxidant activity of the studied products containing Echinacea comes largely from the derivatives of caffeic acid that are present in the extracts of this plant. The use of dietary supplements containing Echinacea extracts, due to their action in preventing oxidative reactions induced by free radicals, may bring health benefits.

Author Contributions: All authors contributed equally to this paper. Conceptualization, F.B., D.M.T. and S.N.; Data curation, P.O., A.C.N. and D.G.; Formal analysis, F.B.; Investigation, F.B., T.B., D.G., F.-M.P. and S.N.; Methodology, S.B. and T.B.; Software, F.B. and T.B.; Supervision, S.B. and T.B.; Validation, P.O. and F.-M.P.; Writing-original draft, F.B., S.B., D.M.T., P.O., A.C.N. and S.N.; Writing—review and editing, S.B., D.M.T. and A.C.N. All authors have read and agreed to the published version of the manuscript.

Funding: This research received no external funding.

Acknowledgments: The authors are thankful to the University of Oradea for all the laboratory facilities.

Conflicts of Interest: The authors declare no conflict of interest. 


\section{References}

1. Hudson, J.B. Applications of the Phytomedicine Echinacea Purpurea (Purple Coneflower) in Infectious Diseases. J. Biomed. Biotechnol. 2012, 2012, 1-16. [CrossRef] [PubMed]

2. Bungau, S.G.; Popa, V.C. Between Religion and Science Some Aspects Concerning Illness and Healing in Antiquity. Transylv. Rev. 2015, 24, 3-18.

3. Hu, C.; Kitts, D.D. Studies on the Antioxidant Activity of Echinacea Root Extract. J. Agric. Food Chem. 2000, 48, 1466-1472. [CrossRef]

4. Vimalanathan, S.; Arnason, J.T.; Hudson, J.B. Anti-inflammatory Activities of Echinacea Extracts Do Not Correlate with Traditional Marker Components. Pharm. Biol. 2009, 47, 430-435. [CrossRef]

5. Burns, J.J.; Zhao, L.; Taylor, E.W.; Spelman, K. The Influence of Traditional Herbal Formulas on Cytokine Activity. Toxicology 2010, 278, 140-159. [CrossRef] [PubMed]

6. Mishima, S.; Saito, K.; Maruyama, H.; Inoue, M.; Yamashita, T.; Ishida, T.; Gu, Y. Antioxidant and Immuno-Enhancing Effects of Echinacea Purpurea. Biol. Pharm. Bull. 2004, 27, 1004-1009. [CrossRef] [PubMed]

7. Zhang, Y.; Tang, T.; He, H.; Wu, H.; Hu, Z. Influence of several postharvest processing methods on polyphenol oxidase activity and cichoric acid content of Echinacea purpurea roots. Ind. Crops Prod. 2011, 34, 873-881. [CrossRef]

8. Pellati, F.; Benvenuti, S.; Magro, L.; Melegari, M.; Soragni, F. Analysis of Phenolic Compounds and Radical Scavenging Activity of Echinacea Spp. J. Pharm. Biomed. Anal. 2004, 35, 289-301. [CrossRef]

9. Zolgharnein, J.; Niazi, A.; Afiuni-Zadeh, S.; Zamani, K. Determination of Cichoric Acid as a Biomarker in Echinacea Purpurea Cultivated in Iran Using High Performance Liquid Chromatography. Chin. Med. 2010, 1, 23-27. [CrossRef]

10. Thygesen, L.; Thulin, J.; Mortensen, A.; Skibsted, L.H.; Molgaard, P. Antioxidant Activity of Cichoric Acid and Alkamides from Echinacea purpurea, Alone and in Combination. Food Chem. 2007, 101, 74-81. [CrossRef]

11. Villaño, D.; Fernández-Pachón, M.S.; Moyá, M.L.; Troncoso, A.M.; García-Parrilla, M.C. Radical Scavenging Ability of Polyphenolic Compounds Towards DPPH Free Radical. Talanta 2007, 71, 230-235. [CrossRef] [PubMed]

12. Bauer, R.; Remiger, P.; Wagner, H. Comparative TLC and HPLC analysis of herbal drugs from Echinacea purpurea, E. pallida and E. angustifolia. Dtsch. Apoth. Ztg. 1988, 128, 174-180.

13. Perry, N.B.; Burgess, E.J.; Glennie, V.L. Echinacea Standardization: Analytical Methods for Phenolic Compounds and Typical Levels in Medicinal Species. J. Agric. Food Chem. 2001, 49, 1702-1706. [CrossRef] [PubMed]

14. Brown, P.N.; Chan, M.; Paley, L.; Betz, J.M. Determination of Major Phenolic Compounds in Echinacea Spp. Raw Materials and Finished Products by High-Performance Liquid Chromatography With Ultraviolet Detection: Single-Laboratory Validation Matrix Extension. J. AOAC Int. 2011, 94, 1400-1410. [CrossRef] [PubMed]

15. Kilmartin, P.A. Electrochemistry applied to the analysis of wine: A mini-review. Electrochem. Commun. 2016, 67, 39-42. [CrossRef]

16. Karaosmanoglu, H.; Suthanthangjai, W.; Travas-Sejdic, J.; Kilmartin, P.A. Electrochemical analysis of beverage phenolics using an electrode modified with poly(3,4-ethylenedioxythiophene). Electrochim. Acta 2016, 201, 366-373. [CrossRef]

17. Abdel-Hamid, R.; Newair, E.F. Adsorptive stripping voltammetric determination of gallic acid using an electrochemical sensor based on polyepinephrine/glassy carbon electrode and its determination in black tea sample. J. Electroanal. Chem. 2013, 704, 32-37. [CrossRef]

18. Makhotkina, O.; Kilmartin, P.A. The use of cyclic voltammetry for wine analysis: Determination of polyphenols and free sulfur dioxide. Anal. Chim. Acta 2010, 668, 155-165. [CrossRef]

19. Zhao, Y.; Tang, Y.; He, J.; Xu, Y.; Gao, R.; Zhang, J.; Chong, T.; Wang, L.; Tang, X. Surface Imprinted Polymers Based on Amino-Hyperbranched Magnetic Nanoparticles for Selective Extraction and Detection of Chlorogenic Acid in Honeysuckle Tea. Talanta 2018, 181, 271-277. [CrossRef]

20. Ribeiro, C.M.; Miguel, E.M.; Silva, J.D.S.; Silva, C.B.D.; Goulart, M.O.F.; Kubota, L.T.; Gonzaga, F.B.; Santos, W.J.R.; Lima, P.R. Application of a Nanostructured Platform and Imprinted Sol-Gel Film for Determination of Chlorogenic Acid in Food Samples. Talanta 2016, 156-157, 119-125. [CrossRef] 
21. Newair, E.F.; Kilmartin, P.A.; Garcia, F. Square wave voltammetric analysis of polyphenol content and antioxidant capacity of red wines using glassy carbon and disposable carbon nanotubes modified screen-printed electrodes. Eur. Food Res. Technol. 2018, 244, 1225-1237. [CrossRef]

22. Daniel, S.; Rao, T.P.; Rao, K.S.; Rani, S.U.; Lee, H.Y.; Kawai, T.; Naidu, G.R.K. A review of DNA functionalized/grafted carbon nanotubes and their characterization. Sens. Actuators B Chem. 2007, 122, 672-682. [CrossRef]

23. Ovádeková, R.; Labuda, J. Electrochemical DNA biosensors for the investigation of dsDNA host-guest interactions and damage. Curr. Opin. Electrochem. 2006, 11, 21-56.

24. Iijima, S. Helical Microtubules of Graphitic Carbon. Nature 1991, 354, 56-58. [CrossRef]

25. Wang, Y.R.; Hu, P.; Liang, Q.L.; Luo, G.A.; Wang, Y.M. Application of Carbon Nanotube Modified Electrode in Bioelectroanalysis. Chin. J. Anal. Chem. 2008, 36, 1011-1016. [CrossRef]

26. Otrisal, P.; Obsel, V.; Forus, S.; Bungau, C.; Aleya, L.; Bungau, S. Protecting emergency workers and armed forces from volatile toxic compounds: Applicability of reversible conductive polymer-based sensors in barrier materials. Sci. Total Environ. 2019, 694. [CrossRef]

27. Qu, L.; Yang, S. Application of Carbon Nanotubes Modified Electrode in Pharmaceutical Analysis. In Carbon Nanotubes_-Growth and Applications; Naraghi, M., Ed.; IntechOpen: Rijieka, Croatia, 2011.

28. Zhao, L.; Gao, L. Novel In Situ Synthesis of MWNTs-Hydroxyapatite Composites. Carbon 2004, 42, 423-426. [CrossRef]

29. Ruel-Gariépy, E.; Chenite, A.; Chaput, C.; Guirguis, S.; Leroux, J. Characterization of Thermosensitive Chitosan Gels for the Sustained Delivery of Drugs. Int. J. Pharm. 2000, 203, 89-98. [CrossRef]

30. Cirillo, G.; Vittorio, O.; Kunhardt, D.; Valli, E.; Voli, F.; Farfalla, A.; Curcio, M.; Spizzirri, U.G.; Hampel, S. Combining Carbon Nanotubes and Chitosan for the Vectorization of Methotrexate to Lung Cancer Cells. Materials 2019, 12, 2889. [CrossRef]

31. Sengiz, C.; Congur, G.; Eksin, E.; Erdem, A. Multiwalled Carbon Nanotubes-Chitosan Modified Single-Use Biosensors for Electrochemical Monitoring of Drug-DNA Interactions. Electroanalysis 2015, 27, 1855-1863. [CrossRef]

32. Fritea, L.; Bănică, F.; Costea, T.O.; Moldovan, L.; Iovan, C.; Cavalu, S. A gold nanoparticles-Graphene based electrochemical sensor for sensitive determination of nitrazepam. J. Electroanal. Chem. 2018, 830-831, 63-71. [CrossRef]

33. Cavalu, S.; Simon, V.; Banica, F. In vitro study of collagen coating by electrodeposition on acrylic bone cement with antimicrobial potential. Dig. J. Nanomater. Biostruct. 2010, 6, 89-97.

34. Singleton, V.L.; Rossi, J.A. Colorimetry of Total Phenolics with Phosphomolybdic-Phosphotungstic Acid Reagents. Am. J. Enol. Vitic. 1965, 16, 144-158.

35. Bondet, V.; Brand-Williams, W.; Berset, C. Kinetics and Mechanisms of Antioxidant Activity using the DPPH.Free Radical Method. LWT Food Sci. Technol. 1997, 30, 609-615. [CrossRef]

36. Zanello, P. Inorganic Electrochemistry: Theory, Practice and Application; The Royal Society of Chemistry, Thomas Graham House: Cambridge, UK, 2003.

37. Hernanz-Vila, D.; Jara-Palacios, M.J.; Escudero-Gilete, M.L.; Heredia, F.J. Applications of Voltammetric Analysis to Wine Products. In Applications of the Voltammetry; Stoitcheva, M., Zlatev, R., Eds.; IntechOpen: Rijieka, Croatia, 2017.

38. Sloley, B.D.; Urichuk, L.J.; Tywin, C.; Coutts, R.T.; Pang, P.K.; Shan, J.J. Comparison of Chemical Components and Antioxidants Capacity of Different Echinacea Species. J. Pharm. Pharmacol. 2001, 53, 849-857. [CrossRef]

39. Oniszczuk, T.; Oniszczuk, A.; Gondek, E.; Guz, L.; Puk, K.; Kocira, A.; Kusz, A.; Kasprzak, K.; Wójtowicz, A. Active Polyphenolic Compounds, Nutrient Contents and Antioxidant Capacity of Extruded Fish Feed Containing Purple Coneflower (Echinacea purpurea (L.) Moench.). Saudi J. Biol. Sci. 2019, 26, 24-30. [CrossRef]

40. Cosio, M.S.; Buratti, S.; Mannino, S.; Benedetti, S. Use of an electrochemical method to evaluate the antioxidant activity of herb extracts from the Labiatae family. Food Chem. 2006, 97, 725-731. [CrossRef]

41. Dar, R.A.; Brahman, P.K.; Khurana, N.; Wagay, J.A.; Lone, Z.A.; Ganaie, M.A.; Pitre, K.S. Evaluation of antioxidant activity of crocin, podophyllotoxin and kaempferol by chemical, biochemical and electrochemical assays. Arab. J. Chem. 2017, 10, S1119-S1128. [CrossRef]

42. Badea, M.; Chiperea, S.; Balan, M.; Floroian, L.; Restani, P.; Marty, J.L.; Iovan, C.; Tit, D.M.; Bungau, S.; Taus, N. New approaches for electrochemical detection of ascorbic acid. Farmacia 2018, 66, 83-87. 
43. Fritea, L.; Tertiş, M.; Cristea, C.; Cosnier, S.; Săndulescu, R. Simultaneous Determination of Ascorbic and Uric Acids in Urine Using an Innovative Electrochemical Sensor Based on $\beta$-Cyclodextrin. Anal. Lett. 2015, 48, 89-99. [CrossRef]

44. Badea, M.; di Modugno, F.; Floroian, L.; Tit, D.M.; Restani, P.; Bungau, S.; Iovan, C.; Badea, G.E.; Aleya, L. Electrochemical Strategies for Gallic Acid Detection: Potential for Application in Clinical, Food or Environmental Analyses. Sci. Total Environ. 2019, 672, 129-140. [CrossRef]

45. Abdel-Hamid, R.; Bakr, A.; Newair, E.F.; Garcia, F. Simultaneous Voltammetric Determination of Gallic and Protocatechuic Acids in Mango Juice Using a Reduced Graphene Oxide-Based Electrochemical Sensor. Beverages 2019, 5, 17. [CrossRef]

46. Glevitzky, I.; Dumitrel, G.A.; Glevitzky, M.; Pasca, B.; Otrisal, P.; Bungau, S.; Cioca, G.; Pantis, C.; Popa, M. Statistical Analysis of the Relationship Between Antioxidant Activity and the Structure of Flavonoid Compounds. Rev. de Chim. 2019, 70, 3103-3107. [CrossRef]

47. Hottaa, H.; Uedaa, M.; Naganoa, S.; Tsujinob, Y.; Koyamac, J.; Osakaia, T. Mechanistic Study of the Oxidation of Caffeic Acid by Digital Simulation of Cyclic Voltammograms. Anal. Biochem. 2002, 303, 66-72. [CrossRef] [PubMed]

48. Newair, E.F.; Abdel-Hamid, R.; Kilmartin, P.A. Mechanism of Chicoric Acid Electrochemical Oxidation and Identification of Oxidation Products by Liquid Chromatography and Mass Spectrometry. Electroanalysis 2016, 28, 1-12. [CrossRef]

49. Zayova, E.; Stancheva, I.; Geneva, M.; Petrova, M.; Vasilevska-Ivanova, R. Morphological evaluation and antioxidant activity of in vitro- and in vivo-derived Echinacea purpurea plants. Open Life Sci. 2012, 7, 698-707. [CrossRef]

(C) 2020 by the authors. Licensee MDPI, Basel, Switzerland. This article is an open access article distributed under the terms and conditions of the Creative Commons Attribution (CC BY) license (http://creativecommons.org/licenses/by/4.0/). 